DOI: https://doi.org/10.24867/02HZ06Renjo

\title{
PROCENA KOLIČINE OLOVA IZ OTPADNIH CRT MONITORA U NOVOM SADU I ANALIZA NJIHOVOG UTICAJA NA ŽIVOTNU SREDINU
}

\section{EVALUATION OF THE QUANTITY OF LEAD FROM THE WASTE CRT MONITORS IN NOVI SAD AND THE ANALYSIS OF THEIR IMPACT ON THE ENVIRONMENT}

\author{
Mirjana Renjo, Bojan Batinić, Fakultet tehničkih nauka, Novi Sad
}

\section{Oblast - INŽENJERSTVO ZAŠTITE ŽIVOTNE SREDINE}

Kratak sadržaj - Postupak rada podrazumeva procenu
količine olova, koji je sadržan u otpadnim televizorima sa
CRT monitorima, za grad Novi Sad, i u zavisnosti od
sadržaja olova, analizu negativnih uticaja na životnu
sredinu $i$ zdravlje ljudi. Dat je pregled raspoloživih $i$
najboljih tehnologija, definisan je scenario, a količina
olova je određena na osnovu eksperimentalno/
istraživačkog dela rada.

Ključne reči: elektronski $i$ električni otpad, CRT, reciklaža

\begin{abstract}
The method of work involves estimating the amount of lead contained in the waste television with CRT monitors for the city of Novi Sad, and depending on the content of lead, the analysis of the negative impacts on the environment and human health. An overview of the available and best technologies is provided, the scenario is defined, and the amount of lead is determined based on the experimental / research part of the work.
\end{abstract}

Keywords: electronic and electrical waste, CRT, recycling.

\section{UVOD}

Elektronska industrija, koju karakteriše najintenzivnija upotreba metala kako sa kvalitativnog tako i kvantitativnog stanovišta, danas predstavlja granu industrije koja se razvija najvećom brzinom i čije se komponente mogu naći u gotovo svakom savremenom proizvodu diktirajući razvoj $\mathrm{i}$ unapređenje mnogih drugih industrijskih grana, poput automobilske industrije, industrije obnovljivih izvora energije, savremene medicine i sl.

U najopštijem smislu, svaki specifičan otpadni tok karakteriše različiti stepen zaostale upotrebne vrednosti čija ponovna upotreba ili finalni tretman mogu biti uslovljeni ekonomskim ili ekološkim faktorima. Potencijali ovih različitih otpadnih tokova predstavljaju jedan od prioriteta u sistemu upravljanja otpadom. Međutim, otpad koji potiče direktno od odbačenih elektronskih i električnih proizvoda (EE otpad) predstavlja materijal čija je prerada danas prioritetan zadatak globalog sistema upravljanja otpadom.

\section{NAPOMENA:}

Ovaj rad proistekao je iz master rada čiji mentor je bio doc. dr Bojan Batinić.
Ova prioritetnost zbrinjavanja i adekvatnog procesiranja e-otpada zapravo je direktno izražena kroz vrlo visok stepen ekonomsko-ekološkog značaja reciklaže ove vrste otpada. Iako klasifikovan kao opasan otpad koji u sebi sadrži neke od najšetnijih i najtoksičnijih materija, poput žive $(\mathrm{Hg})$, olova $(\mathrm{Pb})$, hroma $(\mathrm{Cr})$ ili kadmijuma $(\mathrm{Cd})$, eotpad istovremeno karakteriše vrlo visok sadržaj metala, poput bakra $(\mathrm{Cu})$, aluminijuma $(\mathrm{Al})$, cinka $(\mathrm{Zn})$, nikla (Ni), kalaja (Sn) ili kobalta (Co) ali i vrlo vrednih metala poput zlata $(\mathrm{Au})$, srebra $(\mathrm{Ag})$, platine $(\mathrm{Pt})$ i paladijuma (Pd), što ga čini izuzetno atraktivnim sekundarnim materijalom..

\section{DEFINICIJA, KLASIFIKACIJA, KOLIČINE I SASTAV ELEKTRONSKOG I ELEKTRIČNOG OTPADA}

Iako se ne može reći da postoji jasna definicija, u najopštijem smislu e-otpad se može opisati kao termin koji definiše uredaje koji u svom radu koriste struju a ciji je upotrebni vek prestao. Generalno, ovu vrstu otpada čini veoma širok spektar uređaja i opreme veoma različitih namena, a koji su prema direktivi Evropskog Parlamenta 2002/96/EC svrstani u deset opštih kategorija otpadnih uređaja To su:

1. Veliki kućni aparati;

2. Mali kućni aparati;

3. Oprema informatičke tehnologije (IT) i telekomunikacije (TT);

4. Oprema široke potrošnje za razonodu i fotonaponske ćelije;

5. Oprema za osvetljavanje;

6. Električni i elektronski alati (osim velikih nepokretnih industrijskih alata);

7. Igračke, oprema za rekreaciju i sport;

8. Medicinski pomoćni uredaji (osim implantiranih i infektivnih proizvoda);

9. Instrumenti za praćenje i nadzor;

10. Automati.

Napretkom na polju informacionih tehnologija, unapređenjem postojećih kao i svakodnevnom pojavom novih tipova uređaja i opreme, upotrebni vek ovih uređaja i opreme se drastično skraćuje, što za posledicu ima da se ukupne količine ove vrste otpada uvecavaju sa godišnjom stopom rasta od 3-5\%, a u proseku tri puta brže nego bilo koji drugi čvrsti otpadni tok. Tokom 2014 godine ukupna količina generisanog e-otpada iznosila je 41,8 miliona tona. Međutim, ovi podaci odnose se isključivo na one zemlje koje imaju potpuno implementirane propise i uspostavljena regulatorna tela koji se bave ovom vrstom 
problematike, a što pokriva tek nešto više od 4 milijarde ukupne svetske populacije. Prema podacima Agencije za zaštitu životne sredine, tokom 2014 godine, u Republiku Srbiju uvezeno je preko 14 miliona komada različitih elektronskih i električnih uređaja, pri čemu mali kućni aparati i IT oprema i uređaji (razred II i III) dominiraju sa preko $75 \%$ od ukupnog broja uvezenih uređaja. Sa aspekta materijalnog sastava, električni i elektronski otpad predstavlja vrlo heterogen i kompleksan materijal koji sadrži preko 1000 razlicitih metalnih i nemetalnih materijala, što ovaj otpadni tok istovremeno čini izuzetno vrednom sirovinskom bazom, ali velikim ekološkim problemom. Naime, posmatrajući generalni sastav, preko $60 \%$ ukupne mase čine metali i metalni materijali koji se u naopštijem smislu mogu podeliti u pet podgrupa metala. $\mathrm{Za}$ procenu potencijalne količine elektronskog otpada mogu se koristiti različiti pristupi tj. metode, u zavisnosti od dostupnosti potrebnih podataka. Te metode su:

1. Vremenska postupna metoda

2. Metoda ponude tržišta

3. Carnegi-Mellon metoda

4. Aproksimativna metoda I

5. Aproksimativna metoda II

\section{UTICAJ OPASNIH KARAKTERISTIKA ELEKTRIČNOG I ELEKTRONSKOG OTPADA NA ŽIVOTNU SREDINU I ZDRAVLJE LJUDI}

Zbog opasnih supstanci koje su sadržane u električnim i elektroničkim uređajima, kao što su: toksični metali, npr. berilijum, kadmijum, olovo, živa, šestovalenti hrom itd., električni i elektronski otpad se kategoriše kao opasan otpad i ne sme završiti u komunalnom otpadu, tj. mora se sakupljati odvojeno od ostalog otpada.

Kadmijum - sadrže ga otpornici, infracrveni čitači, poluprovodnici i stariji tipovi katodnih cevi, a koristi se i kao stabilizator u plastici. Kao otrov, taloži se u telu ošteduje bubrege, kosti i sl.

Živa - sadrže je sijalice u ravnim ekranima, sklopke, sva ožičenja u matičnipločama. Napada i razara nervni sistem, izaziva oštedenja osnovne motorijetre, bubrega i svih unutrašnjih organa.

Berilijum - nalazi se na matičnim pločama i konektorima. Klasifikuje se kao kancerogena materija.

Olovo - koristi se u katodnim cevima (CRT). Većina spojeva na matičnim pločama je zaštićena olovom. Olovo je štetno za bubrege, nervni i reproduktivni sistem, usporava mentalni razvoj dece i fetusa.

Barijum - mekani srebrno-beli metal koji se koristi u CRT monitorima, kaozaštita korisnika od zračenja. Kratka izloženost barijumu može da uzrokuje oticanje mozga, slabljenje mišida, oštedenje srca, slezine i jetre.

PVC plastika- najčešće korišćena plastika $u$ elektronskim uređajma, u prosečnom računaru je ima oko $7 \mathrm{~kg}$. Prilikom sagorevanja dolazi do stvaranja dioksina koji može izazvati hormonske poremedaje, oštećenje fetusa, reproduktivnih organa i oštećenja imunog sistema. Polihlorin bifenil (PCB ) - Koristi u transformatorima i kondenzatorima. Iakoje zabranjen za upotrebu u mnogim zemljama, još uvek je prisutan u ee otpadu. Toksični efekti PCB-a uključujudi imunsku supresiju, oštedenje jetre,napredovanje kancera, oštedenje nerava, oštćenje reproduktivnih organa i promene u ponašanju.
Fosfor - koristi se kao premaz unutrašnje strane monitora. Neadekvatnim tretmanom katodnih cevi u vedini slučajeva dolazi do lomljenja CRT monitora i emisije fosfornog premaza u životnu sredinu.

Toneri - Glavni sastojak crnog tonera je pigment. Udisanje je primarni način izlaganja što može dovesti do iritacije disajnih puteva. Klasifikovan je kao kancerogen.

Bromirani inhibitori gorenja (BFR) -koriste se $u$ plastičnim kućištima radi sprečavanja zapaljivosti. Upravljanje otpadnim CRT monitorima i TV aparatima,kao i svim ee-otpadom, regulisano je Pravilnikom o listi električnih i elektronskih proizvoda,merama zabrane i ograničenja korišćenja električne i elektronske opreme koja sadrži opasne materije. Upravljanje elektronskim otpadom, može se podeliti u nekoliko koraka:

1. Sakupljanje, skladištenje

2. Demontaža

3. Mehanički predtretman

4. Napredni tretman/ prečišćavanje

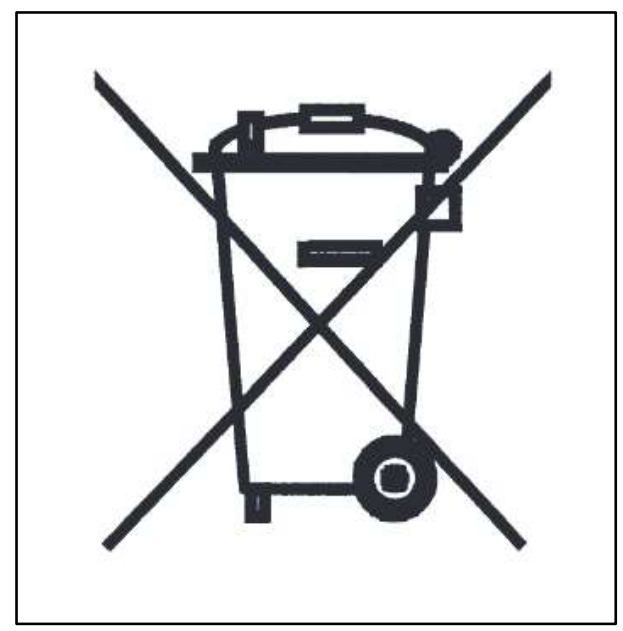

Slika 1. - Znak za odvojeno sakupljanje električnog $i$ elektronskog otpada [2]

Krajnji korisnik predaje distributeru, sakupljaču, operateru ili kolektivnom operateru, osnovanom od strane proizvođača i uvoznika, otpadnu opremu iz domaćinstva uz potvrdu o primopredaji, odnosno, otpadnu opremu koja nije iz domaćinstva uz popunjeni Dokument o kretanju opasnog otpada. Sakupljač otpadnu opremu predaje operateru ili kolektivnom operateru uz popunjeni Dokument o kretanju opasnog otpada. Kako odbačeni CRT monitori i TV aparati predstavljaju opasan otpad, prevoz ove opreme vrši se vozilima registrovanim za ADR transport $\mathrm{tj}$. vozilima registrovanim za prevoz opasnih tereta. Postoji veliki broj barijera za primenu koncepta ponovne upotrebe. Među najvažnijima su brzi razvoj tehnologija, brza promena mode $\mathrm{i}$ zahteva $\mathrm{u}$ pogledu funkcionalnosti proizvoda; nemogućnost dovođenja starog proizvoda na moderni nivo zbog nedostatka predprojektovanih svojstava i cena popravke neispravnih proizvoda koja može da prevaziđe cenu novog modernog proizvoda. Trenutno, najčešća rešenja predstavljaju deponije i izvoz ee otpada. Odlaganje otpada na deponije jedan je od najcešcih nacina za odlaganje eotpada, uprkos tome što je opasan. Kod svih deponija je primeceno ispuštanje materija u okolinu do neke mere, što 
znaci da teški metali i druge otrovne supstance iz e-otpada mogu da iscure i zagade zemljište $i$ vodu.

\section{ZAKONSKA REGULATIVA \\ 4.2.1 Direktiva o otpadnoj električnoj i elektronskoj opremi, WEE direktiva (WASTE OF ELECTRONIC AND EELECTRICAL EQUIPMENT)}

Prva Direktiva je (WEEE), o električnom i elektronskom otpadu, teži da poboljša upravljanje električnim otpadom i da podstakne proizvođače da proizvode uređaje imajući u planu njihovu reciklažu. Ključni deo ove Direktive jeste da su proizvođači odgovorni za troškove vezane za sakupljanje, obnavljanje, reciklažu i tretman električnog otpada. Svrha ove Direktive jeste prevencija električnog otpada i ponovna upotreba, reciklaža i obnavljanje, kako bi se smanjilo odlaganje ovakve vrste otpada. Takođe ona nastoji da poboljša ekološke performanse svih operatera angažovanih u životnom ciklusu proizvoda (proizvođača, distributera, potrošača i ostalih, koji su direktno uključeni u tretman WEEE). Od 2006. godine bilo koji proizvod koji ne zadovoljava zahteve WEEE Direktive ne može da se proda na tržištu Evropske Unije. Kompanije koje žele da prodaju svoje proizvode na tržištu EU moraju da se registruju u svakoj od zemalja članica kao snabdevači. Ova registracija obuhvata detaljan plan o tome, kako se svaka kompanija povinuje zahtevima WEEE Direktive. 4.3 DRUGA DIREKTIVA EU, "ROHS"

Druga Direktiva je, "RoHS" (Restriction of the use of hazardoues substances) - Direktiva o ograničenjima za upotrebu opasnih materija i dopunjuje WEEE Direktivu ograničenjem količina potencijalno opasnih materijala sadržanih u električnim aparatima. RoHS Direktiva EU je obavezna da se sprovodi i postane zakon u svakoj državi članici. Ova Direktiva 2002/95/EC, od 1. jula 2006. godine ograničava upotrebu šest opasnih materija u proizvodnji raznih vrsta elektronske i električne opreme: olovo, živu, kadmijum, šestovalentni hrom, polibromni bifenil (Pbbs) i polibromni bifenil etri (PBDEs). U okviru ove Direktive postoji i posebna Direktiva o baterijama, usvojena 2006. godine kojom se reguliše proizvodnja, odlaganje i trgovina baterija u Evropskoj uniji. RoHS Direktiva se odnosi na električne i elektronske uređaje koji su obuhvaćeni kategorijama u Aneksu IA WEEE Direktive. RoHS u svojim specifikacijama tačno određuje koliki procentualni udeo teških metala i kontrolisanih supstanci u odnosu na masu svaka komponenta može da sadrži.

\section{ANALIZA SADRŽAJA OLOVA U STARIM TELEVIZORIMA SA CRT CEVIMA KOJI SE GENERIŠU NA TERITORIJI GRADA NOVOG SADA}

Glavni ciljevi istraživanja su procena količine otpadnih televizora sa katodnim CRT cevima na teritoriji grada Novog Sada, određivanje sadržaja olova koji završi u životnoj sredini, i ispitivanje uticaja prethodno analiziranog sadržaja olova, na životnu sredinu i zdravlje ljudi. U cilju istraživanja, sprovedena je anketa u domaćinstvima kao primarni izvor informacija o zastupljenosti i količinama televizora sa CRT monitorom. Anketa je sprovedena na teritoriji grada Novog Sada, pri čemu su ključni parametri bili: broj članova porodica i uzrast (godine). Takođe, kao bitan parametar prilikom istraživanja, može se uzeti i ukupno primanje domaćinstva na mesečnom nivou $\mathrm{i} / \mathrm{ili}$ godišnjem nivou. Broj porodica koje su sarađivale prilikom sprovođenja ankete je 10. Kao što je već spomenuto, razvoj elektronnke tehnologije je nikad brži, pa se samim tim televizori sa CRT monitorom zamenjuju sa LCD, Plazma televizorima. Tokom sprovođenja ankete i analize, porodice koje poseduju CRT televizore, navele su širok spektar razloga zbog čega nisu zamenjeni, a najčešći razlozi su: nedovoljna finansijska sredstva, „nezainteresovanost“ za savremenom tehnologijom, pa čak i višak prostora. Na osnovu tabele može se uočiti da od ukupno 10 domaćinstava, tj. ukupan broj članova je 28, koji su učestvovali $\mathrm{u}$ anketi, samo 4 porodice poseduju televizor sa CRT monitorom. Drugim rečima, $40 \%$ od ukupno posmatranog domaćinstva. Poseban problem kod CRT monitora predstavljaju visoke koncentracije olova i nemogućnosti dobijanja potpuno čistog (oslobođenog bilo kakve nečistoće) stakla koje bi moglo ponovo da se iskoristi. Katodne cevi , u proseku sadrže $20 \%$ olova (zbog zaštite potrošača od zračenja), što iznosi 1 do 2 kilograma po jedinici. Na osnovu proračuna, dobijenih rezultata i literurnih podataka, može se odrediti količina olova koji je sadržan u uređajima i koji se oslobodi u medijume životne sredine, izazivajući negativan efekat. Primenom scenarija koji je obrađen $u$ poglavlju, procenjeno je da četiri porodice od deset, poseduju po jedan CRT televizor, što znači da ukupna količina uređaja iznosi četiri. Uzimajući u obzir dobijenu,prosečnu vrednost olova, $0.9 \mathrm{~kg}$, za svaki, pojedinačno uređaj, dobija se krajnji rezultat, sadržaj olova iznosi 3,6 kg. Kao i u prethodnom proračunu koji se odnosi konkretno na anketu, primenićemo podatak i za slučaj celog grada Novog Sada, da uređaj sadrži $0.9 \mathrm{~kg}$ olova. Krajnji rezultat, sadržaj olova iznosi $9.925,2 \mathrm{~kg}$.

\section{NEGATIVAN UTICAJ OLOVA NA ŽIVOTNU SREDINU I ZDRA VLJE LJUDI}

Najznačajnija i sve veća upotreba olova u elektronskoj opremi je u displejima i monitorima katodne cevi (CRT). Olovo u katodnim, CRT cevima deluje kao zaštitni radijator i snižava temperatutu topljenja stakla. Do sada je više puta dokazano da olovo ima kancerogene efekte na zdravlje ljudi, ali i da to nije jedina negativna posledica.

Kod biljaka koje su izložene visokim dozama olova dolazi do pojave simptoma toksikacije kao što su zakržljao rast, hloroza, tamnija boja korenovog sistema i brza inhibicija rasta korenova. Olovo inhibira fotosintezu, dolazi do poremećaja u mineralnoj ishrani i vodnom balansu, utiče na hormonski status, oštećuje strukturu i permeabilnost membrana, izaziva oksidativni stres kod biljaka itd.

U zavisnosti od stepena idustrijalizacije, meteoroloških i topografskih uslova i frekvencije saobraćaja, količina olova u vazduhu kreću se od $1-3 \neg \mathrm{g} / \mathrm{m}^{3}$. Olovo se iz vazduha taloži na zemljište tako da se od $8-20 \mathrm{mg} / \mathrm{kg} \mathrm{u}$ nekultivisanom zemljištu može govoriti o $10.000 \mathrm{mg} / \mathrm{kg} \mathrm{u}$ zemljištu u blizini industrijskog izvora zagađivanja i 403 $\mathrm{mg} / \mathrm{kg}$ olova u zemljištu $u$ blizini frekventne saobraćajnice. Olovo je tipičan otrov koji u organizam čoveka dospeva preko respiratornog i gastroinetinalnog trakta. Svakodnevno unošenje ovog metala u količini od 2 
mg može za nekoliko meseci dovesti do trovanja. Za različite koncentracije olova u krvi dokazane su sledeće posledice po zdravlje:

1. Akutni efekti (efekti koji se momentalno ispoljavaju)

2. Hronični efekti (dugotrajni efekti).

\subsection{IZBOR OPTIMALNOG REŠENJA}

Kako se svaka supstanca ponaša drugačije, na kraju radnog veka, za svaku vrstu elektronskog otpadai električnog otpada, potrebno je razmotriti da li je poželjno da se otpad reciklira, spali (insineracija) ili odloži na deponiju. Prilikom deponovanja, otpadna elektronska i električna oprema, doprinosi značajnoj količini teških metala i halogenih materija, u tokovima komunalnog otpada. Negativni uticaji na životnu sredinu, koji karakterišu tretman deponovanja, usko su povezani sa električnim i elektronskim otpadom koji se takođeodlaže na deponije. Izlivanje $\mathrm{i}$ isparavanje teških metala i drugih toksičnih materija, odnosno, kontaminacija zemljišta i podzemnih voda , kao i zauzimanje prostora ,predstavljaju jedan od glavnih problema odlaganja na deponije.

Metali iz sijalica i CRT-a, koji se nalaze u električnoj i elektronskoj opremi, koji se oslobođaju na deponijama su olovo i živa. Recikliranje u širem smislu smatra se poželjnom opcijom za upravljanje otpadom. Reciklaža elektronskog i električnog otpada se sastoji od četiri koraka:

1. Sakupljanje

2. Predtretman

3. Sortiranje i razdvajanje

4. Obrada

Recikliranje zatvorenog tipa je zastupljeno $u$ industrijskom obimu, i predstavlja reciklažu otpadnih CRT-a u cilju dobijanja novih CRT-a. U ovom procesu, staklo je podeljeno na dve kategorije, staklo koje ne sadrži olovnu ploču i staklo koje sadrži olovo. Odvojenost panel i stakla postiže se primenom raznih metodama ( metode laserskog zračenja, metoda vodenog mlaza itd.) koje su prethodno navedne. Ova metoda predstavlja veliki napredak upravljanja CRT-om. U poređenju sa deponovanjem i spaljivanjem, ovaj pristup je ekonomski i ekološki prihvatljiv. Druga predložena forma reciklaže je reciklaža otvorene petlje, koja se trenutno istražuje širom sveta i privlači pažnju za veliki broj studija. Reciklaža otvorene petlje podrazumeva upotrebu otpadnih CRT-a u cilju dobijanja novih proizvoda, širokog spektra. Ovaj pristup je trenutno vrlo atraktivan jer nudi ekološke i enomoske koristi.

\section{ZAKLJUČAK}

Prvi korak ka mogućem unapređenju sistema upravljanja ee otpadom, jeste podizanje svesti građana i informisanje o elektronskom otpadu, karakteristikama, opasnim materijama, načinu odlaganja, na različite načine. Takođe, jedno od rešenja može se predstaviti u vidu primene odgovarajućih mera, kako bi se što manje količine elektronskog i električnog otpada, odlagale na deponije zajedno sa komunalnim otpadom i kako bi se postigao visok procenat odvojenog sakupljanja, sto podrazumeva bolju kontrolu nadležnih institucija i sektora. Generalno rečeno, pooštravanje zakonske regulative u ovoj oblasti, u Republici
Srbiji je neophodno za dalja unapređenja. U radu su analizirane dve forme reciklaže, kao optimalna rešenja, pri čemu se reciklažom starih CRT monitora mogu dobiti novi CRT monitori ili širok spektar novih proizvoda. Izborom ove tehnologije, kao rešenje, sprečiće se kontaminacija zemljišta, podzemnih voda kao i emisije u vazduhu, pojava požara na deponijama, a postići će se ušteda sirovina i energije.

\section{LITERATURA}

[1] Ranitović, M. B. (2016). Integralni hidrometalurški postupak reciklaže metala iz električnog i elektronskog otpada sa tehno-ekonomskim aspektima, dr. disertacija. Beograd,Srbija:Tehnološko-metalurški fakultet, Univerzitet u Beogradu.

[2] Batinić, B. (2017). Elektronski otpad, predavanje. Upravljanje posebnim tokovima otpada. Novi Sad: Fakultet tehničkih nauka.

[3] Marković, N. (2011). Upravljanje otpadnim CRT monitorima i TV aparatima.

[4] Ćurčić, S., Pavlović, M., Arsovski, S., Pavlović, A., \& Tomović, A. (2011). Direktive EU u upravljanju elektronskim otpadom.

[5] Milojković, J., \& Stojilković, S. (2006). Postupci prerade računara na kraju životnog veka. Beograd: Zbornik radova 50. Konferencije za ETRAN. [6] Agbaba, J. (2017). Ekotoksičnost metala. Prirodno matematički fakultet, Departman za hemiju.

[7] Five Winds International, LP. (2001). An

Environmental Scan of Toxic and Hazardous Materials in IT and Telecom Products and Waste.

[8] Ledwaba, P., \& Sosibo, N. (2016). E-waste Management in South Africa: Case Study:Cathode Ray Tubes Recycling Opportunities. Bazel, Švajcarska. [9] Đunisijević Bojović, D. M. (2013). Uticaj koncentracije olova i kadmijuma u zemljištu na razvoj drvenastih biljaka, Dr. disertacija. Beograd: Šumarski fakultet, Univerzitet u Beogradu.

\section{Kratka biografija}

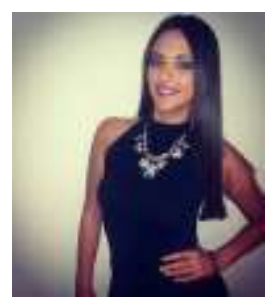

Mirjana Renjo rođena je 03. oktobra 1994. godine u Novom Sadu. Osnovnu školu završila je u Novom Sadu, kao i srednju tehničku školu „Pavle Savić““, tehničar za zaštitu životne sredine, 2013. godine. Diplomski rad na Fakultetu tehničkih nauka iz oblasti Inženjerstva zaštite životne sredine, odbranila je 2017. godine. Master akademske studije upisala je 2017. godine na Fakultetu tehničkih nauka, na istom studijskom programu.

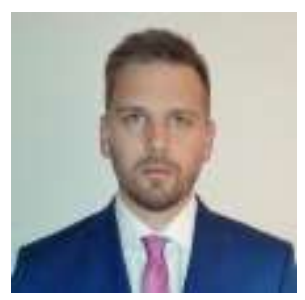

Bojan Batinić rođen je 1981. godine u Zagrebu. Master studije na studijskom programu inženjerstvo zaštite životne sredine na Fakultetu tehničkih nauka iz Novog Sada je završio 2008. godine. Doktorirao je 2015. godine na Fakultetu tehničkih nauka $\mathrm{i}$ iste godine izabran je u zvanje docenta. 